\title{
Temporary threshold shifts in fingertip vibratory sensation from hand-transmitted vibration and repetitive shock
}

\author{
S Maeda, M J Griffin
}

\begin{abstract}
Temporary threshold shifts (TTSs) in vibrotactile perception produced by continuous vibration and repetitive shock have been investigated. Subjects were exposed to vertical hand-transmitted $100 \mathrm{~Hz}$ continuous vibration and various repetitive shocks of equal energy content formed from one complete cycle of a $100 \mathrm{~Hz}$ sine wave. The repetition rate of the cycles was $5,25,50$, or $100 \mathrm{~s}^{-1}$ while the root-mean-square (rms) acceleration measured over exposures of five minutes was held constant at $2 \cdot 5,5$, or $10 \mathrm{~ms}^{-2} \mathrm{rms}$ (weighted according to British Standard (BS) 6842 and International Standard (ISO) 5349). A control condition with no vibration was also included. Subjects held a handle with $10 \%$ of their maximum hand grip force. When exposed to five shocks per second at each of the three frequency-weighted acceleration magnitudes the subjects developed a small TTS. Exposure to 100 shocks per second (continuous vibration) at each of the three frequency-weighted acceleration magnitudes caused a large TTS, although the total frequency-weighted energy was the same as when exposed to five shocks per second. The relation between the TTS, the logarithm of the shock repetition rate, and the logarithm of the frequency-weighted rms acceleration was described by the relation TTS $=-16 \cdot 256+11 \cdot 812 \log _{10} R+15 \cdot 179 \log _{10} a_{\text {hw }}$, where TTS is the temporary threshold shift, $R$ is the shock repetition rate, and $a_{h w}$ is the frequency-weighted rms acceleration according to BS 6842 and ISO 5349. The results suggest
\end{abstract}

Department of Industrial Engineering, Faculty of Science and Technology, Kinki University, Kowakae 3-4-1, Higashiosaka City, Osaka 577, Japan

S Maeda

Human Factors Research Unit, Institute of Sound and Vibration Research, University of Southampton, Southampton SO9 $5 \mathrm{NH}$

M J Griffin that the equal energy hypothesis underlying BS 6842 and ISO 5349 is inappropriate for the prediction of the TTS produced by repetitive shocks.

\section{(British Journal of Industrial Medicine 1993;50:360-367)}

International Standard (ISO) $5349^{1}$ and British Standard (BS) $6842^{2}$ are primarily concerned with protecting workers from incurring vibrationinduced white finger (VWF) and other aspects of the socalled hand-arm vibration syndrome. These standards use measures of the frequency-weighted acceleration to express the severity of hand-transmitted vibration exposures in terms of the predicted number of years before finger blanching indicates vascular disorders. Both standards provide information on how the vibration magnitude associated with $10 \%$ prevalence of vascular symptoms may depend on daily and lifetime periods of exposure to vibration. The assessment of hand-transmitted vibration is based on daily exposure to vibration expressed as eight hour or four hour "energy equivalent" frequency-weighted root-mean-square (rms) acceleration. This procedure defines a time dependency in which the vibration magnitude may be doubled if the exposure time is reduced by a factor of four. This time dependency is convenient because it enables exposures to be quantified using rms averaging, but its adoption has not been based on the results of experimental research or epidemiological studies.

Radzyukevich $^{3}$ suggested that the temporary threshold shifts (TTSs) in vibrotactile thresholds at the end of a working day were correlated with the permanent threshold shifts (PTSs), which develop over a longer period. Malinskaya $e \mathrm{al}^{4}$ found that the mean TTS of workers after a day of work that included vibration exposure, corresponded to the PTS of vibratory sensation that occurred in that group after 10 years of exposure. These findings might suggest that the TTS after daily exposure may be used to indicate the PTS after prolonged exposure to vibration. It would therefore be desirable to be able to predict the TTS from measurements of the daily exposure to vibration. Such studies will be of 
Table 1 Experimental conditions (exposure time was 5 minutes; grip force was $10 \%$ of maximum hand grip force)

\begin{tabular}{|c|c|c|c|c|c|c|}
\hline \multirow[b]{2}{*}{$\underline{a_{h s s}\left(m s^{-2} r m s\right)}$} & \multicolumn{4}{|c|}{ Repetition rate $\left(\mathrm{s}^{-1}\right)$} & \multirow[b]{2}{*}{$a_{h e(\text { eq, } 8 h)}$} & \multirow[b]{2}{*}{$a_{h e v / \text { eq, } 4 h,}$} \\
\hline & 100 & 50 & 25 & 5 & & \\
\hline $\begin{array}{r}2.5 \\
5.0 \\
10.0\end{array}$ & $\begin{array}{l}0 \\
0 \\
0\end{array}$ & $\begin{array}{l}0 \\
0 \\
0\end{array}$ & $\begin{array}{l}0 \\
0 \\
0\end{array}$ & $\begin{array}{l}0 \\
0 \\
0\end{array}$ & $\begin{array}{l}0.255 \\
0.510 \\
1.021\end{array}$ & $\begin{array}{l}0 \cdot 361 \\
0 \cdot 722 \\
1 \cdot 443\end{array}$ \\
\hline
\end{tabular}

interest in evaluating the risks of damage to neurological processes involved in vibrotactile sensations, but they may not be relevant to vascular changes.

The prediction of TTSs after exposure to continuous vibration has been investigated by various researchers. ${ }^{5-12}$ Results have been obtained showing the effects of variables such as the frequency of sinusoidal vibration, the magnitude of continuous vibration, the exposure time, and the grip force. The relative importance of shocks and continuous vibration in the production of the various vibration injuries and vibrotactile TTSs is not well understood. The TTS after exposure to the repetitive shock characteristics of many vibrating tools cannot be predicted from the results of previous studies.

This investigation was undertaken to compare measurements of the short term effects of repetitive shock and continuous vibration on vibratory perception thresholds with the methods given in current International and British standards for evaluating hand-transmitted vibration. The operating hypothesis was that exposure to continuous vibration and repetitive shocks would produce equal vibrotactile TTSs when the repeated shocks and the continuous vibration have equal frequency-weighted rms acceleration.

\section{Methods}

VIBRATION GENERATION AND CALIBRATION

Many percussive metal working tools generate high magnitude shocks that recur at some rate, often between 15 and $100 \mathrm{~s}^{-1} \cdot{ }^{1314}$ To compare the effects of continuous vibration and shocks with equal frequency-weighted rms acceleration on the TTS, the experimental conditions given in table 1 were used. The shock repetition rate labelled $100 \mathrm{~s}^{-1}$ in table 1 was continuous sinusoidal vibration with a frequency of $100 \mathrm{~Hz}$. Figure 1 shows examples of the desired acceleration time histories with the stimuli having equal frequency-weighted rms acceleration. The stimuli were generated using the HVLab computer system. ${ }^{15}$

The eight hour energy equivalent frequencyweighted rms acceleration for an exposure to a single period of constant rms frequency-weighted acceleration, $\mathrm{a}_{\mathrm{hw}}$, of duration $t$ seconds is given by:

$$
\mathrm{a}_{\mathrm{hw}}(\mathrm{eq}, 8 \mathrm{~h})=\mathrm{a}_{\mathrm{hw}}\left[t / \mathrm{T}_{(8)}\right]^{1.2}
$$

where $T_{8}$ is $28800 \mathrm{~s}$ (eight hours), $a_{\mathrm{hw}}$ is the constant rms frequency-weighted acceleration, and $t(\mathrm{~s})$ is the duration of the single period of constant rms frequency-weighted acceleration (The four hour energy equivalent frequency-weighted rms acceleration can be calculated by substituting $T_{(4)}(14400 \mathrm{~s})$ in place of $T_{(8)}$ ).

The frequency-weighted $\mathrm{rms}$ acceleration on the

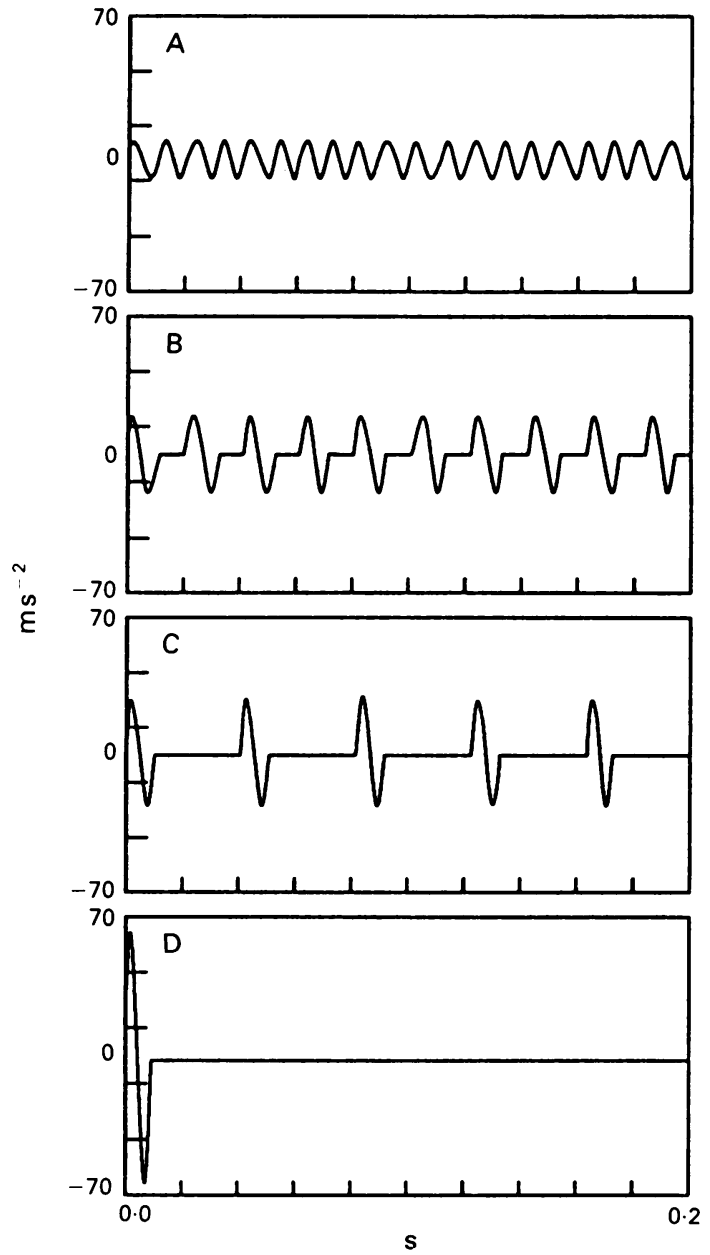

Figure 1 Desired acceleration time histories for $2.5 \mathrm{~ms}^{-2} \mathrm{rms}$ stimuli. (A) $100 \mathrm{~s}^{-1}$ (continuous $100 \mathrm{~Hz}$ vibration); (B) $50 s^{-1}$; (C) $25 s^{-1}$; (D) $5 s^{-1}$. 

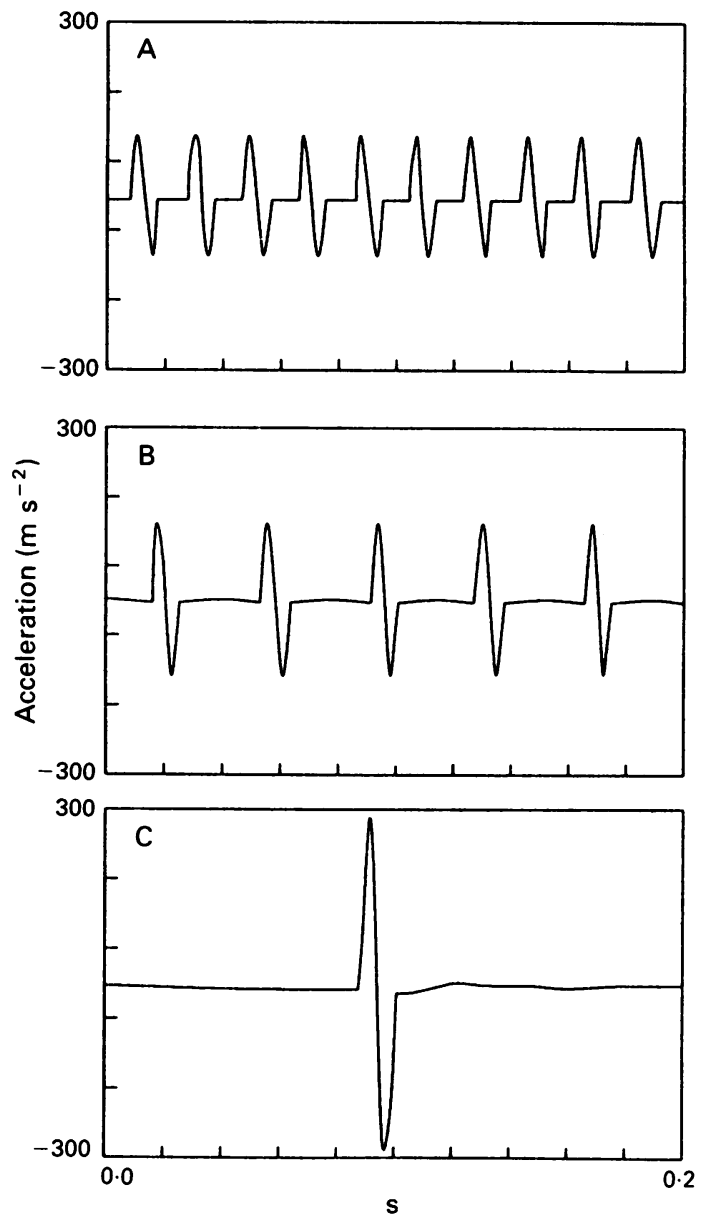

Figure 2 Acceleration time histories achieved on handle of vibrator for $10 \mathrm{~ms}^{-2} \mathrm{rms}$ stimuli. (A) $50 \mathrm{~s}^{-1} ;$ (B) $25 \mathrm{~s}^{-1}$; (C) $5 s^{-1}$.

vibrating handle was measured with the HVLab system, which was calibrated using a vibration reference source (Bruel and Kjaer type 4292). The accelerometer signals were conditioned by a charge amplifier (Kistler 5001) and low pass filtered at 1260 $\mathrm{Hz}$ to prevent aliasing and then digitised by a 12 bit analogue to digital converter at a rate of 5000 samples per second. Analysis of digitised vibration data was also carried out with the HVLab software package. Acceleration time histories of three seconds duration were used to calculate power spectral density functions. The power spectra had a resolution of $2 \cdot 46 \mathrm{~Hz}$ and 32 degrees of freedom.

For good reproduction of the desired acceleration waveforms it was necessary to compensate for the response of the vibrator. Equalisation was performed by the following method. At the first step, the vibrator transfer function was measured with the
HVLab system. The system's impulse response $h(t)$ was convolved with the input signal $\mathrm{w}(t)$ to obtain the output signal $\mathrm{p}(t)$ :

$$
\mathrm{p}(t)=\mathrm{w}(t) \cdot \mathrm{h}(t)
$$

Because direct calculation of this convolution is lengthy, it is preferable to work in the frequency domain, for which the equation becomes:

$$
\mathbf{P}(f)=\mathbf{W}(f) . \mathbf{H}(f)
$$

where $\mathbf{P}(f), \mathbf{W}(f)$ and $\mathbf{H}(f)$ are Fourier transforms of the time histories $\mathrm{p}(t), \mathrm{w}(t)$, and $\mathrm{H}(t)$ respectively. The transfer function, $H(f)$ of the vibrator was thereby calculated. The following calculation was then performed:

$$
A(f)=1 / H(f)
$$

where $\mathbf{A}(f)$ is the spectrum required to general a flat spectrum on the vibrator. The required time function to be introduced into the system was then calculated from the required shock signal $\mathrm{s}(t)$ and the impulse response of the spectrum $A(f)$ :

$$
\mathbf{x}(t)=\mathrm{s}(t) \cdot \operatorname{Imp}\{\mathrm{A}(f)\}
$$

where $\mathrm{s}(t)$ is the shock signal and Imp signifies the impulse response calculation of the spectrum. The time function $\mathrm{x}(t)$ was introduced into the vibration system with shock repetition rates of 50,25 , and $5 \mathrm{~s}^{-1}$. Figures $2 \mathrm{~A}$ to $2 \mathrm{C}$ show the corresponding measured acceleration waveforms on the vibrating handle. Equalisation of the vibrator response was well achieved by this method. The frequency-weighted rms acceleration was calculated from the power spectral density functions with the formula:

$$
a_{h w}=\left[\int_{f=8}^{f=1024} H_{w}^{2}(f) G(f) \mathrm{d} f\right]^{1 / 2}
$$

where $\mathrm{G}(f)$ is the power spectral density function and $\mathrm{H}_{\mathrm{w}}(f)$ is the weighting function such as that specified in ISO 5349. ${ }^{1}$ Octave band $\mathrm{rms}$ values for centre frequencies from 8 to $1024 \mathrm{~Hz}$ were also calculated from the spectral density functions. Figure 3 shows the graphs of the octave band analysis as a function of frequency. The spectral content was similar for all stimuli but with increasing low frequency content as the shock repetition rate reduced.

SUBJECTS

Four subjects aged 22 to 31 participated in the study. All were healthy male research workers at the University of Southampton with no history of neuromuscular or vascular disorders, and who had not suffered any serious injuries to the upper extremities. No subject had previous occupational experience operating powered hand tools. Table 2 summarises subject hand strength and anthropometry. 


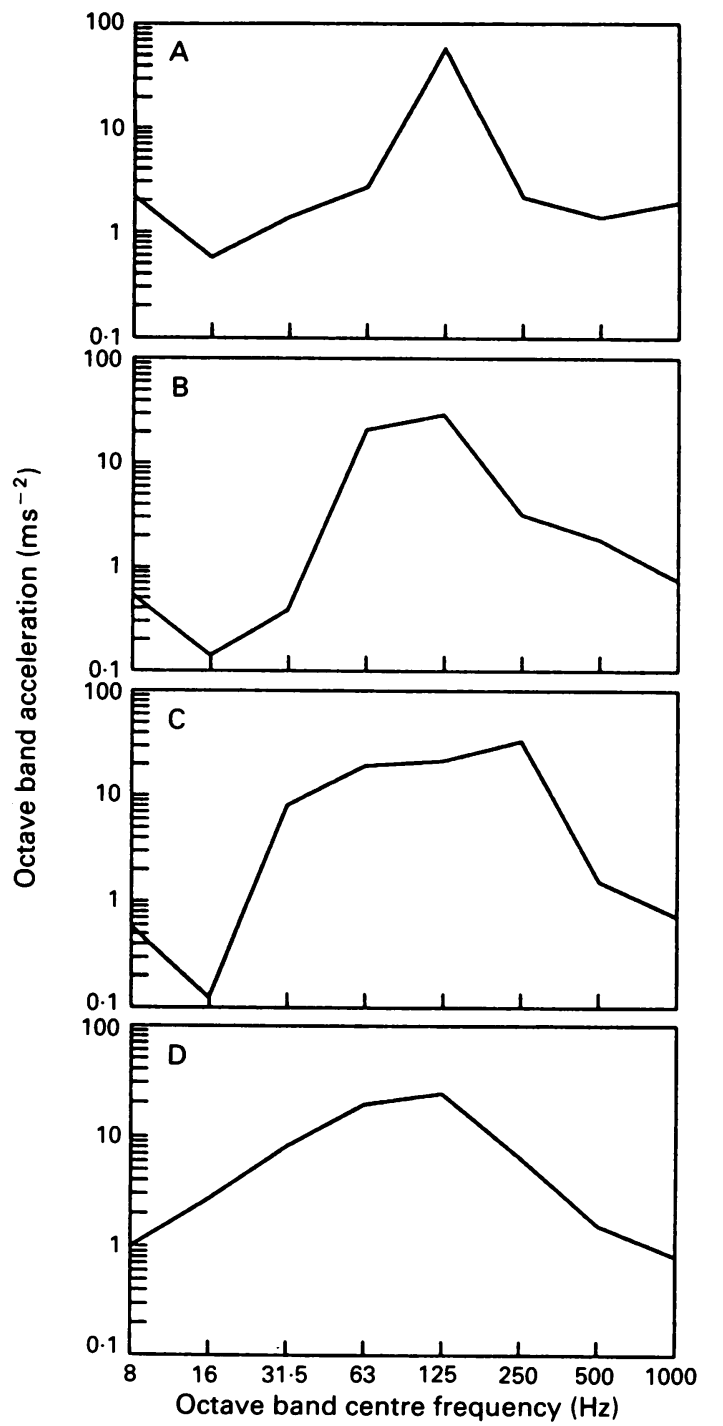

Figure 3 Octave band spectra (A) $100 \mathrm{~s}^{-1}$; (B) $50 \mathrm{~s}^{-1}$; (C) $25 s^{-1}$; (D) $5 s^{-1}$.

\section{TESTING PROCEDURE}

The instruction sheet shown in appendix $\mathbf{A}$ was presented to each subject before the experiment began. To study the TTS in fingertip vibratory sensation, the vibratory sensation threshold was measured before and after subjects were exposed to hand-transmitted vibration. The experiment was carried out in a sound proof and thermoregulated room. Room temperature was held in the range 20 to $24^{\circ} \mathrm{C}$.

Vibration was applied to the left hand through a handle attached to an electrodynamic vibrator (VP30, Derritron, Hastings, England) for five minutes. Each subject was seated with his left forearm laid on a horizontal arm stand and clasped the vibrating handle. The push and pull forces were controlled at zero. The subject was instructed to clasp the handle tightly and constantly with the fleshy part of the palm with the required hand grip force in a relaxed posture. The grip force was $10 \%$ of the maximum hand grip force of each subject. Grip force and pushing-pulling force were monitored by calibrated strain gauge bridges attached to the handle. The subject watched a meter to maintain his grip force at the appointed level. To prevent the subject's hand from being too cool, the temperature of the handle was thermostatically controlled at $30^{\circ} \mathrm{C}$.

The vibrotactile threshold measurement system used in the present study has been described previously. ${ }^{8}$ The threshold of $125 \mathrm{~Hz}$ vibratory sensation was measured at the tip of the index finger of the left hand. The vibrotactile apparatus consisted of a counterbalanced vibrator carrying a $6 \mathrm{~mm}$ diameter perspex tipped circular contactor, extending up through a $10 \mathrm{~mm}$ diameter solid perspex surround. This contactor touched the finger with a contact force of $1 \mathrm{~N}$. The push force (force applied on the contactor and surround by the subject's finger tip) was $1 \mathrm{~N}$ and it was monitored by using a feedback system to the subject. The method of minimal change was employed, the subject depressing a hand-held response button when he could feel the vibration. The rate of stimulus change was rapid over the first change of response so as to ensure that the threshold would be quickly reached even if it lay some distance from the initial level. The threshold was calculated by a microcomputer from the mean of six successive decisions of the subject. This procedure took 60 to 120 seconds for each threshold determination. Consecutive sessions were separated by at least 12 hours. Appendix B shows the sequence of events in each session. The noise level during the vibration exposure was 50 to $59 \mathrm{~dB}(\mathrm{~A})$. During the

Table 2 Subject anthropometry and hand strength

\begin{tabular}{lllll}
\hline Subject & Age $(y)$ & Height $(\mathrm{cm})$ & Weight (kg) & Maximum grip force (N) \\
\hline 1 & 22 & 170 & 70 & 38 \\
2 & 25 & 175 & 66 & 43 \\
3 & 31 & 184 & 73 & 73 \\
4 & 23 & 180 & 74 & 45 \\
\hline
\end{tabular}

All subjects were men. 
Table $3 T T S(d B)$ immediately after vibration exposure

\begin{tabular}{|c|c|c|c|c|}
\hline Repetition rate $\left(\mathrm{s}^{-1}\right)$ & Subjects & $2.5 \mathrm{~ms}^{-2} \mathrm{rms}$ & $5 \mathrm{~ms}^{-2} \mathrm{rms}$ & $10 \mathrm{~ms}^{-2} \mathrm{rms}$ \\
\hline 100 & $\begin{array}{l}1 \\
2 \\
3 \\
4\end{array}$ & $\begin{array}{l}13 \cdot 2 \\
15.2 \\
13.1 \\
12.7\end{array}$ & $\begin{array}{l}15 \cdot 5 \\
21.0 \\
20.5 \\
14.9\end{array}$ & $\begin{array}{l}27 \cdot 1 \\
25 \cdot 3 \\
22 \cdot 9 \\
17 \cdot 5\end{array}$ \\
\hline 50 & $\begin{array}{l}1 \\
2 \\
3 \\
4\end{array}$ & $\begin{array}{r}8 \cdot 8 \\
12 \cdot 4 \\
10 \cdot 5 \\
7 \cdot 1\end{array}$ & $\begin{array}{l}15.0 \\
15.6 \\
13.8 \\
17.9\end{array}$ & $\begin{array}{r}20.1 \\
13.1 \\
19.9 \\
9.5\end{array}$ \\
\hline 25 & $\begin{array}{l}1 \\
2 \\
3 \\
4\end{array}$ & $\begin{array}{l}4 \cdot 1 \\
5 \cdot 1 \\
3 \cdot 7 \\
2 \cdot 5\end{array}$ & $\begin{array}{r}6.5 \\
10.4 \\
13.1 \\
9.9\end{array}$ & $\begin{array}{r}8 \cdot 1 \\
13 \cdot 1 \\
19.9 \\
9.5\end{array}$ \\
\hline 5 & $\begin{array}{l}1 \\
2 \\
3 \\
4\end{array}$ & $\begin{array}{l}0 \cdot 1 \\
0 \cdot 2 \\
0 \cdot 1 \\
0 \cdot 25\end{array}$ & $\begin{array}{l}0.9 \\
4 \cdot 2 \\
4 \cdot 1 \\
0.5\end{array}$ & $\begin{array}{r}6 \cdot 3 \\
5 \cdot 3 \\
10 \cdot 0 \\
7 \cdot 2\end{array}$ \\
\hline Control condition & $\begin{array}{l}1 \\
2 \\
3 \\
4\end{array}$ & $\begin{array}{l}1 \cdot 6 \\
2 \cdot 1 \\
1.3 \\
1.5\end{array}$ & $\begin{array}{l}- \\
-\end{array}$ & $\begin{array}{l}- \\
z\end{array}$ \\
\hline
\end{tabular}

measurement of the vibratory sensation thresholds (before and after the vibration exposure) the noise level was 30 to $32 \mathrm{~dB}(\mathrm{~A})$.

The subjects attended for thirteen sessions. Twelve sessions involved exposure to one of three acceleration levels at one of four repetition rates. The acceleration of the applied vibration was maintained at $2 \cdot 5,5$, or $10 \mathrm{~ms}^{-2} \mathrm{rms}$, the repetition rate was either $100 \mathrm{~s}^{-1}$ (continuous sinusoidal vibration) or 50,25 , or $5 \mathrm{~s}^{-1}$. One session involved no exposure to vibration. The test sequences were presented in a random order.

\section{Results}

Table 3 shows the threshold shifts. Although the frequency-weighted "energy" was equal for all 12 vibration stimuli, the TTS after exposure to vibration clearly depended on the shock repetition rate. The TTS decreased for decreasing shock repetition rates from $100 \mathrm{~s}^{-1}$ to $5 \mathrm{~s}^{-1}$ for each of the three levels of frequency-weighted rms acceleration. Compared with the control condition in which subjects clasped the handle but were not exposed to vibration, the exposure to vibration induced a significant $(p<0.05)$ increase in TTS according to the test of the difference between means for independent groups (see fig 4). The one exception was with the lowest shock repetition rate of $5 \mathrm{~s}^{-1}$ and the lowest acceleration magnitude of $2.5 \mathrm{~ms}^{-2} \mathrm{rms}$.

Table 4 shows the result of multifactor analysis of variance. The effect of the magnitude of the frequency-weighted rms acceleration was statistically significant $(p<0.01)$. The effect of the repetition rate was also statistically significant $(\mathrm{p}<$ 0.01 ). The subject effect was statistically significant $(\mathrm{p}<0.05)$ and may be partially due to the difference in the maximum hand grip force of each subject. This affected the grip used in the experiment and may have altered the vibration transmitted to the hands of different subjects.

\section{Discussion}

Table 5 shows a comparison of the TTS estimated with the $100 \mathrm{~Hz}$ sine wave with the results of previous studies. Harada ${ }^{5}$ and Harada and Griffin ${ }^{6}$ used a large plate to expose the hand to vibration and measured TTS in the vibration sense at 63,125 , and $250 \mathrm{~Hz}$. Maeda and $\mathrm{Kume}^{9}$ used a handle and investigated the TTS of vibration sense at $125 \mathrm{~Hz}$ under various conditions of exposure. Although in these studies the

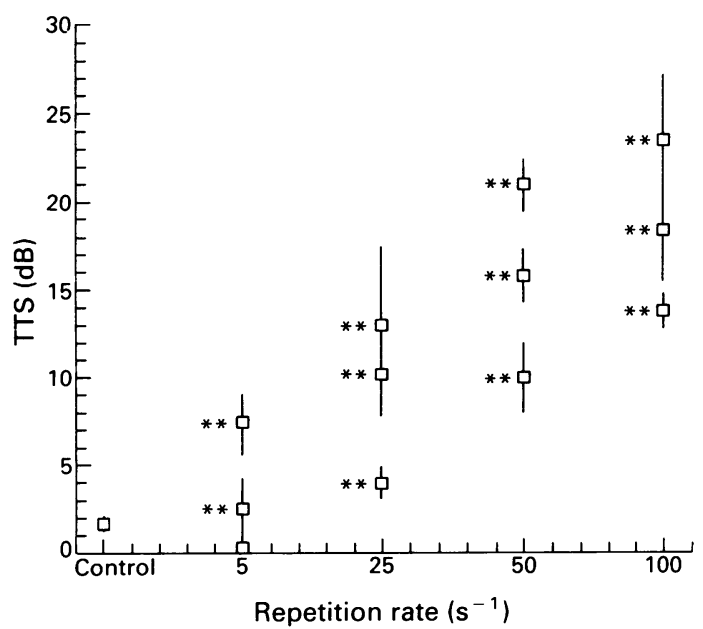

Figure 4 Mean (SD) of TTS. $\left({ }^{\star \star} p<0.01\right.$ : significant difference from control condition according to the test of difference between means). 
Table 4 Analysis of variance summary table for vibrotactile threshold data

\begin{tabular}{|c|c|c|c|c|}
\hline Main effects & Sums of squares & Degrees of freedom & Mean square & F Ratio \\
\hline $\begin{array}{l}\text { A (acceleration) } \\
\text { B (repetition) } \\
\mathbf{C} \text { (subjects) } \\
\mathbf{A} \times \mathbf{B} \\
\mathbf{A} \times \mathbf{C} \\
\mathbf{B} \times \mathbf{C} \\
\text { Errors }\end{array}$ & $\begin{array}{c}668 \cdot 33 \\
1624 \cdot 6 \\
75 \cdot 856 \\
29 \cdot 265 \\
31 \cdot 819 \\
54 \cdot 761 \\
91 \cdot 044\end{array}$ & $\begin{array}{r}2 \\
3 \\
3 \\
6 \\
6 \\
9 \\
18\end{array}$ & $\begin{array}{c}334 \cdot 17 \\
541 \cdot 54 \\
25 \cdot 285 \\
4 \cdot 8776 \\
5 \cdot 3032 \\
6 \cdot 0846 \\
5 \cdot 0580\end{array}$ & $\begin{array}{c}66 \cdot 07^{\star \star} \\
107 \cdot 07^{\star \star} \\
5 \cdot 00^{\star} \\
0.96 \\
1.05 \\
1.20\end{array}$ \\
\hline Total & $257 \cdot 7$ & 47 & - & - \\
\hline
\end{tabular}

${ }^{\star} \mathrm{p}<0.05 ;{ }^{\star \star} \mathrm{p}<0.01$.

Table 5 Comparison of results with previous studies

\begin{tabular}{llll}
\hline$a_{\text {hw }}\left(\mathrm{ms}^{-2} \mathrm{rms}\right)$ & $\begin{array}{l}\text { Present study } \\
\left.\text { (repetition rate } 100 \mathrm{~s}^{-1}\right)(\mathrm{dB})\end{array}$ & $\begin{array}{l}\text { Harada and } \\
\text { Harada and Griffin }\end{array}$ \\
\hline $2 \cdot 5$ & 13.60 & 14.07 & $12 \cdot 8$ \\
5 & 18.03 & $17 \cdot 26$ & $17 \cdot 8$ \\
10 & 23.27 & 20.97 & 23.9 \\
\hline
\end{tabular}

vibration sense thresholds were measured differently, the TTSs for $100 \mathrm{~Hz}$ vibration (a shock repetition of $100 \mathrm{~s}^{-1}$ ) are similar to those in the present study.

Maeda and $\mathrm{Kume}^{10}$ have proposed a prediction equation for the TTS after exposure to stationary vibration having an arbitrary spectral shape. Table 6 shows a comparison of the measured TTSs with the results calculated according to the method of Maeda and Kume. ${ }^{10}$ Although the equation can predict the TTS after exposure to stationary vibration having an arbitrary spectral shape it does not predict the results of the present study.

In Table 3, the TTS after exposure to shocks is seen to be much less than after exposure to continuous vibration, even though the frequency-weighted energy applied to the hand by the shocks and the continuous vibration was the same. The principal difference between the stimuli may be the amount of recovery between successive shocks: perhaps the faster rate of repetition does not allow recovery before the ensuing shocks cause a greater amount of TTS.

When the frequency-weighted vibration magnitude was constant according to British and International standards, the effects on vibratory sensation threshold should have remained constant if the weighting system was effective at preventing neurological impairment. The results indicate that the vibration frequency weighting and time weighting did not account for the effects of hand-transmitted shock on the TTS. The result of this experiment suggests that the equal energy hypothesis underlying both BS 6842 and ISO 5349 is an inappropriate basis for predicting the TTS produced by exposure to repetitive shock vibration.

Alternative methods were considered for the growth of TTS with increasing repetition rate when there is equal frequency-weighted rms acceleration.
It was assumed that there was a linear relation between the TTS (measured in dB), the logarithm of the shock repetition rate, and the logarithm of the frequency-weighted rms acceleration. This was approximated by the following equation:

$$
\operatorname{TTS}(\mathrm{dB})=\mathrm{a}_{0}+\mathrm{a}_{1} \cdot \log _{10} \mathrm{R}+\mathrm{a}_{2} \cdot \log _{10} \mathrm{a}_{\mathrm{hw}}
$$

where $a_{0}, a_{1}$, and $a_{2}$ are the coefficients of the regression equation, $R$ is the repetition rate, and $a_{h w}$ is the frequency-weighted $\mathrm{rms}$ acceleration. Linear regression analysis was conducted on the measured TTS values as a function of the shock repetition rate, $R$, and the frequency-weighted rms acceleration, $a_{h w}$. The regression equation was given by:

TTS $=-16 \cdot 256+11 \cdot 812 \cdot \log _{10} R+15 \cdot 179 \cdot \log _{10} a_{\text {hw }}$ Table 7 compares the measured TTS with that predicted by the regression equation. Figure 5 shows the relation between the TTS, $\log _{10} R$ and $a_{h w}$. The multiple correlation coefficient $(r=0.9794)$ was highly significant $(\mathrm{p}<0.01)$.

The comparative importance of shocks and continuous vibration in the production of the various vibration injuries is not well understood but there is

Table 6 Comparison of results with previous studies

\begin{tabular}{|c|c|c|c|}
\hline $\begin{array}{l}\text { Repetition } \\
\text { rate }\left(s^{-1}\right)\end{array}$ & $a_{h w}\left(m s^{-2} r m s\right)$ & $\begin{array}{l}\text { Measurements: } \\
\text { present study } \\
\text { (mean value dB) }\end{array}$ & $\begin{array}{l}\text { Prediction: } \\
\text { Maeda and } \\
\text { Kume }^{10}(d B)\end{array}$ \\
\hline 50 & $\begin{array}{l}2 \cdot 5 \\
5 \\
10\end{array}$ & $\begin{array}{r}9.75 \\
15.63 \\
20.78\end{array}$ & $\begin{array}{l}16 \cdot 50 \\
18 \cdot 30 \\
20 \cdot 10\end{array}$ \\
\hline 25 & $\begin{array}{l}2 \cdot 5 \\
5 \\
10\end{array}$ & $\begin{array}{r}3.91 \\
10 \cdot 03 \\
12 \cdot 71\end{array}$ & $\begin{array}{l}15 \cdot 69 \\
17 \cdot 49 \\
19 \cdot 29\end{array}$ \\
\hline 5 & $\begin{array}{l}2 \cdot 5 \\
5 \\
10\end{array}$ & $\begin{array}{l}0 \cdot 19 \\
2 \cdot 48 \\
7 \cdot 24\end{array}$ & $\begin{array}{l}15 \cdot 99 \\
17 \cdot 79 \\
19 \cdot 50\end{array}$ \\
\hline
\end{tabular}


Table 7 Comparison of calculated and measured TTS results

\begin{tabular}{lccc}
\hline$a_{\text {hw }}\left(\mathrm{ms}^{-2} \mathrm{rms}\right)$ & $\begin{array}{l}\text { Repetition } \\
\text { rate }\left(\mathrm{s}^{-1}\right)\end{array}$ & $\begin{array}{c}\text { Experiment } \\
T T S(d B)\end{array}$ & $\begin{array}{c}\text { Prediction } \\
T T S(d B)\end{array}$ \\
\hline 2.5 & 5 & $0 \cdot 19$ & -1.96 \\
& 25 & 3.91 & 6.30 \\
& 50 & $9 \cdot 75$ & $9 \cdot 85$ \\
5 & 100 & 13.60 & 13.41 \\
& 5 & $2 \cdot 48$ & $2 \cdot 61$ \\
& 25 & 10.03 & $10 \cdot 87$ \\
10 & 50 & $15 \cdot 63$ & $14 \cdot 42$ \\
& 100 & 18.03 & 17.98 \\
& 5 & $7 \cdot 24$ & $7 \cdot 18$ \\
& 25 & 12.71 & $15 \cdot 44$ \\
& 50 & $20 \cdot 78$ & 18.99 \\
& 100 & 23.27 & 22.55 \\
\hline
\end{tabular}

some evidence that injury to the bones and joints is particularly associated with tools producing low frequency shocks. ${ }^{13}$ The TTS in vibrotactile sensitivity after exposure to shock vibration is also not well understood. From fig 5 of the present study, the relation between the growth of the TTS after exposure to conditions of hand-transmitted repetitive shock and vibration can be represented by a straight line. It was found that the TTS decreased if the frequency-weighted rms acceleration was held constant when the repetition rate decreased.

When the frequency-weighted rms acceleration is constant, the effect of the repetition rate on the TTS can be expressed as $3.56 \mathrm{~dB}$ per doubling of the repetition rate. When the repetition rate is constant the effect of vibration magnitude on TTS can be expressed as $4.6 \mathrm{~dB}$ per doubling of acceleration magnitude. For an energy time dependency, the $\mathrm{dB}$ change in TTS for a doubling of the acceleration magnitude should be twice the $\mathrm{dB}$ change in TTS produced by a doubling of the repetition rate. The results of this experiment suggest that, compared

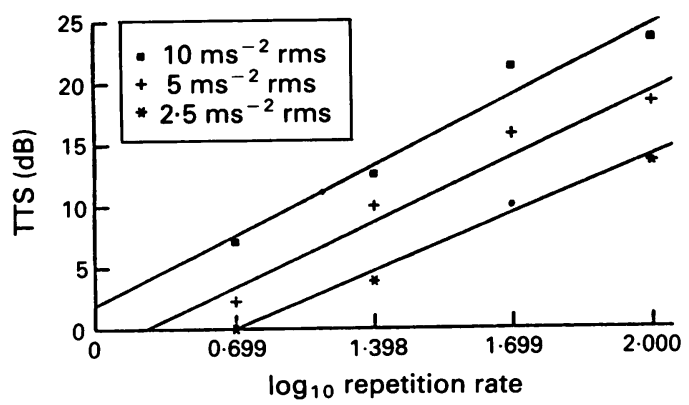

Figure 5 Relation between the TTS (dB) and the logarithm of the repetition rate $(R)$ for three magnitudes of vibration $\left(a_{\mathrm{hw}}\right)$ :

$\left(T T S=-16 \cdot 256+11 \cdot 812 \log _{10} R+15 \cdot 179 \log _{10} a_{\mathrm{hw}}\right)$. with the effect of vibration magnitude, the repetition rate is more important than implied by an energy time-dependency.

The physiological mechanisms responsible for the present results are not clear. It would seem useful to conduct further research on the TTS after exposure to shock vibration with variable repetition rates, variable frequency-weighted $\mathrm{rms}$ acceleration, and variable vibration frequency.

Knowledge of the influence of many physical parameters, such as the spectral content, the duration, the waveform, the repetition rate, the exposure time, the vibration magnitude, the grip force, and the contact area, is required if safety criteria for handtransmitted repetitive shock and vibration relevant to neurological disorders are to be properly established.

\section{Conclusion}

The study investigated the TTS produced by continuous vibration and repetitive shock. The conclusions are: (1) when the vibration transmitted to the hand by repetitive shocks and continuous vibration had equal frequency-weighted rms acceleration (weighted according to ISO $5349^{1}$ and BS $6842^{2}$ ) the TTSs after vibration exposure were not of equal magnitude. (2) The rate of repetition of shocks is a significant variable in determining the TTS. (3) The equal energy hypothesis underlying ISO 5349 and BS 6842 is an inappropriate basis for predicting the TTS produced by repetitive shocks. (4) The growth of TTS after exposure to hand-transmitted repetitive shock having a constant frequency-weighted rms acceleration is proportional to the logarithm of the shock repetition rate. (5) The TTS decreases when the frequency-weighted rms acceleration is held constant and the shock repetition rate is decreased.

\section{Appendix A}

These are instructions that were given to the subjects taking part in the experiment on the exposure of continuous and shock vibration to the hand.

\section{INSTRUCTIONS TO SUBJECTS}

The aim of this experiment is to clarify the relation between the effects of hand-transmitted continuous and shock vibration on temporary threshold shift of fingertip vibratory sensation.

Before the vibration exposure, the vibratory sensation threshold and the maximum grip force of your hand will be measured.

You will be seated with your left forearm laid on a horizontal armstand and clasping the vibrating handle.

Vibration will be applied to the left hand through a handle attached to an electrodynamic vibrator for five minutes. The handle will vibrate at a frequencyweighted rms acceleration of $2 \cdot 8 \mathrm{~ms}^{-2} \mathrm{rms}$.

Your task is to clasp the vibrating handle with $10 \%$ 
of your maximum grip force during vibration exposure.

After five minutes vibration exposure, the vibratory sensation threshold of your fingertip will be measured.

You may stop the experiment at any time by pressing the STOP button.

Thank you for taking part in this experiment.

\section{Appendix B}

AN EXPERIMENTAL SESSION TABLE

\begin{tabular}{llllll} 
A & B & C & $\begin{array}{l}\text { D } \\
\text { sons }\end{array}$ & E & \\
\hline 0 & 3 & 5 & 8 & 13 & 15 \\
Start & & Min & & & End
\end{tabular}

A: Instruction sheet presented to subjects before the start of the experiment.

B: Maximum grip force measurement (only first session).

C: Fingertip vibratory sensation threshold measurement.

D: Vibration exposure with $10 \%$ maximum grip force.

E: Immediately after vibration exposure, fingertip vibratory sensation threshold measurement.

This study was performed in the Human Factors Research Unit, Institute of Sound and Vibration Research, University of Southampton, England. We thank all the members for their collaboration and useful discussions. This overseas research was supported by Kinki University, Japan.
1 International Organization for Standardization. Mechanical vibration guidelines for the measurement and the assessment of human exposure to hand-transmitted vibration. Geneva: 1986:ISO 5349.

2 British Standards Institution. British Standard guide to measurement and evaluation of human exposure to vibration transmitted to the hand. London: 1987:BS 6842.

3 Radzyukevich TM. Interrelation of temporary and permanent shifts of vibration and pain sensitivity threshold under the effect of local vibration. Gig Tr Prof Zabol 1969;12:20-3.

4 Malinskaya NN, Filin AP, Shkarinov LN. Problem of occupational hygiene in operating mechanised tools. Vestnik Akademii Meditsinkikh USSR 1964;19:31-6.

5 Harada N. Studies on the changes in the vibratory sensation threshold at the fingertip in relation to some physical parameters of exposed vibration. Part 1 . A study on the methods of vibration exposure and measurement of the vibratory sensation threshold. Japanese Journal of Hygiene 1978a;33:699-705.

6 Harada N. Studies on the changes in the vibratory sensation threshold at the fingertip in relation to some physical parameters of exposed vibration. Part 2. A study on the equal TTS curves of the vibratory sensation and the hygienic allowable limit of portable mechanized tool. Japanese Journal of Hygiene 1978b;33:706-17.

7 Nishiyama K, Watanabe S. Temporary threshold shift of vibratory sensation after clasping a vibrating handle. Int Arch Occup Environ Health 1981;49:21-33.

8 Hayward R. Temporary threshold shifts in vibrotactile sensitivity: effects of vibration duration, intensity and frequency. Proceedings of UK informal group meeting on human response to vibration, Heriot-Watt University, Edinburgh, 21-22 September 1984:36-46.

9 Maeda S, Kume Y. Temporary threshold shift on finger-tip vibratory sensation induced by exposure to octave band vibration. Journal of the Japan Industrial Management Association 1978;38:243-8.

10 Maeda S, Kume Y. Temporary threshold shift of finger-tip vibratory sensation induced by exposure to spectrum vibration. Journal of the Japanese Industrial Manufacturing Association 1989;40:336-42.

11 Maeda S, Kume Y. Temporary threshold shift of finger-tip vibratory sensation induced by exposure to intermittent vibration (on the exposure-equivalent rule). Journal of the Japanese Industrial Manufacturing Association 1991;42: 105-11.

12 Harada N, Griffin MJ. Factors influencing vibration sense thresholds used to assess occupational exposure to handtransmitted vibration. Br J Ind Med 1991;48:185-92.

13 Griffin MJ. Handbook of human vibration, London: Academic Press, 1990.

14 Nelson CM, Griffin MJ. Vibration-induced white finger in dockyard employees. Southampton: Institute of Sound and Vibration Research, University of Southampton, 1989. Technical report No 170 .

15 Nelson CM, Lewis $\mathrm{CH}$. Techniques for the measurement and prediction of vehicle vibration. Proceedings of $U K$ informal group meeting on human response to vibration, AFRC Institute of Engineering Research, Silsoe, 21-22 September 1989:1-15.

Accepted 8 June 1992 